\title{
Formulation and in vitro Evaluation of Floating Tablets of Dicloxacillin Sodium Using Different Polymers
}

\author{
Haranath Chinthaginjala1,*, Gandla Chaitanya Barghav ${ }^{1}$, Challa Mahesh Reddy ${ }^{1}$, Bhupalam Pradeepkumar ${ }^{3}$, Hindustan Abdul Ahad ${ }^{2}$ \\ 'Department of Pharmaceutics, Raghavendra Institute of Pharmaceutical Education and Research, Anantapur, Andhra Pradesh, INDIA. \\ 2Department of Industrial Pharmacy, Raghavendra Institute of Pharmaceutical Education and Research, Anantapur, Andhra Pradesh, INDIA. \\ ${ }^{3}$ Department of Pharmacology, Raghavendra Institute of Pharmaceutical Education \& Research, Anantapur, Andhra Pradesh, INDIA.
}

\begin{abstract}
Objectives: The purpose of the work was to develop gastro retentive floating tablets of Dicloxacillin sodium using different ratios of HPMC K 100M, Xanthan gum, Guar gum. Sodium bicarbonate is used as a gas generating agent. Dicloxacillin sodium is used to treat a wide variety of bacterial infections and has a half-life of about $2 \mathrm{hr}$. Methods: Gastro retentive floating tablets containing $270 \mathrm{mg}$ of dicloxacillin sodium were prepared by wet granulation method employing different ratios of polymers. Results: The formulated tablets were evaluated for precompression parameters and were in the acceptable limits. Post-compression parameters such as weight variation, hardness, friability, swelling index, floating lag time and total floating time were also evaluated. The formulation F3 with HPMC K $100 \mathrm{M}$ showed $98.87 \%$ of drug release at the end of $12 \mathrm{hr}$, maintained integrity of tablets and have an optimum floating lag time of $90 \pm 0.14 \mathrm{sec}$ and total floating time of $12 \mathrm{hr}$. The optimized formulation F3 was fitted to various kinetic models and the results showed that F3 formulation followed Zero order kinetics with an $R^{2}$ value of
\end{abstract}

0.993. The mechanism of drug release from F3 formulation was non-fickian diffusion. Conclusion: The study concluded that, among all the developed formulations, F3 formulation floated up to $12 \mathrm{hr}$ with maximum drug release and can be considered as promising formulation.

Key words: Dicloxacillin sodium, Floating tablets, HPMC K100M, Swelling index, Buoyancy.

Correspondence

Dr. Haranath Chinthaginjala,

Associate Professor, Department of Pharmaceutics, Raghavendra Institute of pharmaceutical, Education and Research, Anantapur-515721, Andhra Pradesh, INDIA.

Phone: +91-9959072207

Email: haranathriper@gmail.com

DOI: 10.5530/jyp.2019.11.51

\section{INTRODUCTION}

Oral drug delivery is the most preferred route of drug delivery due to the ease of administration and patient compliance. Gastric emptying is a complex process that is highly variable and alters in vivo performance of drug delivery systems. ${ }^{1,2}$ Floating system is a low-density system that floats over the gastric content and tending to keep afloat in the stomach without affecting the gastric emptying rate for a prolonged period. ${ }^{3,4}$ While the system floating on the gastric content, drug is released slowly from the system at the desired rate, after the release of the drug, the system is emptied from the stomach. This results in increased GRT and better control of fluctuation of plasma drug concentration. ${ }^{5}$ Polymers are used in floating system so as to target the drug delivery at a specific region in the GI tract i.e. stomach. Both synthetic and natural polymers are used in floating drug delivery. Natural polymers used in the floating system are Guar gum, Chitosan, xanthan gum, Gellan gum, Sodium alginate. Synthetic polymers used for the floating drug delivery are HPMC, Eudragit, ethyl cellulose. ${ }^{6}$ Dicloxacillin sodium is used to treat a wide variety of bacterial infections. It is a penicillin-type antibiotic. It works by stopping the growth of bacteria. The half-life of the drug is $2 \mathrm{hr}$ which requires frequent drug administration. Conventional tablets of Dicloxacillin sodium requires more dosing frequency. Hence an attempt was made to develop the floating tablets of Dicloxacillin sodium to decrease the dosing frequency, releasing the drug in a controlled manner for a prolonged period and to improve the bioavailability of the drug. ${ }^{7.8}$

\section{MATERIALS AND METHODS}

Dicloxacillin sodium was received as a gift sample from DRL Hyderabad. HPMC K100 M, Xanthan gum, Guar gum, Sodium bicarbonate, Citric acid, Starch, Magnesium Stearate, MCC, Talc were procured from Yarrow Chem, Mumbai, India. All chemicals used were of analytical grade. Preformulation studies

\section{Compatibility studies by FTIR}

Dicloxacillin sodium was analyzed by FTIR spectroscopy using potassium bromide pellet method. The powdered sample of the drug with different polymers was mixed thoroughly with previously dried potassium bromide. The powder mixture was transferred into hydraulic press and pressure was applied for a few sec (10,000 Psi) and released, a thin transparent pellet was formed. ${ }^{9}$ The samples were scanned in the range of 4000 to $400 \mathrm{~cm}^{-1}$.

\section{Analytical method development}

$100 \mathrm{mg}$ of dicloxacillin sodium pure drug was dissolved in $100 \mathrm{ml}$ of 0.1 $\mathrm{N} \mathrm{HCl}$ (stock solution $1000 \mu \mathrm{g} / \mathrm{ml}$ ). From this $10 \mathrm{ml}$ of solution was taken and the volume was adjusted to $100 \mathrm{ml}$ with $0.1 \mathrm{~N} \mathrm{HCl}(100 \mu \mathrm{g} / \mathrm{ml})$. From this $10 \mathrm{ml}$ of solution was taken and the volume adjusted to $100 \mathrm{ml} 0.1 \mathrm{~N}$ $\mathrm{HCl}(10 \mu \mathrm{g} / \mathrm{ml})$. The above solution was subsequently diluted with $0.1 \mathrm{~N}$ $\mathrm{HCl}$ to obtain a series of concentrations in the range of 1.0 to $6.0 \mu \mathrm{g} / \mathrm{ml}$. The absorbance of the above concentrations was measured at $263 \mathrm{~nm}$ by UV- Spectrophotometer using $0.1 \mathrm{~N} \mathrm{HCl}$ as the blank. ${ }^{10}$

\section{Method of preparation}

The floating tablets were prepared by wet granulation method, using different polymers HPMC K 100 M, Xanthan gum and Guar gum in differ-

This is an open access article distributed under the terms of the Creative Commons Attribution-NonCommercial-ShareAlike 4.0 License, which allows others to remix, tweak, and build upon the work non-commercially, as long as the author is credited and the new creations are licensed under the identical terms. 
ent ratios (Table 2). The ingredients were weighed accurately and mixed thoroughly. The granulation was done with the starch paste by passing through 10 mesh. The granules were dried in tray dryer at $45^{\circ} \mathrm{C}$. The dried granules were sized through 22 mesh followed by lubricated with magnesium stearate and talc and then compressed using Rimek compression machine. $^{11}$

\section{Evaluation of Precompression parameters}

\section{Angle of repose}

Fixed funnel method was used to measure the flow properties where the granules were poured from funnel walls to form conical heap in which its lower tip is $2-5 \mathrm{~cm}$ away from the hard surface. ${ }^{12}$ The static angle of repose was measured by using the formula,

$\theta=\operatorname{Tan}-1(\mathrm{~h} / \mathrm{r}) / \mathrm{h}$ - the height of the heap, $\mathrm{r}$ - radius of the heap

\section{Bulk and tapped density}

The blend was sieved to ensure free from agglomeration free and was introduced into a calibrated measuring cylinder. The initial volume was observed and then the cylinder was allowed to tap onto a hard surface from $2.5 \mathrm{~cm}$ height. The tapping was continued to get saturated volume. From the above values, both poured bulk density and tapped density were determined. ${ }^{13}$

\section{Hausner's ratio and compressibility index}

Hausner's found that the ratio of tapped volume and poured volume was related to its interparticle friction and can be used as a direct tool for flow property evaluation. Compressibility index was determined by using the formula ${ }^{14}$

$$
\begin{gathered}
\text { compressibility index }=\frac{\text { Tapped densityy index }=\text { of ta }}{\text { Tapped density }} \times 100 \\
\text { Hausner Ratio }=\frac{\text { Tapped density }}{\text { Bulk density }}
\end{gathered}
$$

\section{Post Compression Parameters}

\section{Thickness and weight variation test}

Randomly selected 6 tablets were subjected for thickness measurements by using vernier calipers. To study the weight variation, 20 tablets of each formulation were weighed individually using an electronic balance, calculating the average weight and comparing the individual tablets weight to the average. ${ }^{15}$

\section{Drug content}

To evaluate the drug content, 10 tablets of same weight were selected and crushed using mortar and pestle. Powder equivalent to the average weight of the tablet was weighed and dissolved in $0.1 \mathrm{M} \mathrm{HCl}$ and diluted suitably. The concentration of drug in the samples was detected using Ultraviolet (UV)-visible spectrophotometer. ${ }^{16}$

\section{Hardness and friability}

Tablets from each formulation were subjected for crushing strength and friability by using the Monsanto hardness tester (Cadmach, Ahmedabad, India) and the Roche friabilator (electro lab, Mumbai, India), respectively. ${ }^{17}$

\section{Swelling studies}

The swelling properties of tablets were determined by placing the tablet in the dissolution test apparatus containing $900 \mathrm{ml}$ of $0.1 \mathrm{~N} \mathrm{HCl}$ and maintained at $37 \pm 0.5^{\circ} \mathrm{C}$. At periodic time intervals, the tablets were taken out of the medium and the weight gain in each tablet was checked using electronic weighing balance. The swelling characteristics were ex- pressed in terms of the percentage of water uptake (WU \%) according to the equation. ${ }^{18}$

$$
\text { WU }=\frac{\text { weight of the swollen tablet C. Atial weight of the tablet }}{\text { initial weight of the tablet }} \times 100
$$

\section{In vitro buoyancy study}

The in vitro buoyancy was determined by observing the floating lag time and the total floating duration (floating capacity). Floating lag time was determined using $900 \mathrm{ml}$ of $0.1 \mathrm{~N} \mathrm{HCl}$ and three tablets were placed in it. The time required for the tablet to rise from the bottom to the surface of the media was recorded. The time was observed visually and recorded using a stopwatch. The total floating time was determined by placing three individual tablets from each formulation in a beaker containing $900 \mathrm{ml}$ of $0.1 \mathrm{~N} \mathrm{HCl}$. Then the time taken for each tablet to constantly float on the media was measured. ${ }^{19}$

\section{In vitro dissolution Study}

The dissolution study was conducted using $900 \mathrm{ml}$ of $0.1 \mathrm{~N} \mathrm{HCl}$ as dissolution medium employing USP apparatus-II (Paddle Method). The medium was allowed to equilibrate to the temperature of $37 \pm 0.5^{\circ} \mathrm{C}$. Tablet was placed in the vessel and operated the apparatus for $12 \mathrm{hr}$ at $50 \mathrm{rpm}$. Samples were withdrawn at defined time intervals and replaced with fresh medium. Suitable dilutions were done with $0.1 \mathrm{~N} \mathrm{HCl}$ and analyzed spectrophotometrically at $263 \mathrm{~nm}$ using UV-spectrophotometer. ${ }^{20}$

\section{Kinetic modeling of drug release}

To analyze the drug release mechanism of the Dicloxacillin sodium floating tablets, the in vitro dissolution data of formulations were fitted to zero order, first order, Higuchi model and Korsmeyer Peppas model. ${ }^{21}$

\section{Stability studies}

The accelerated stability studies were conducted employing screwcapped bottle to pack the optimized formulation and studies were carried out for 3 months, by maintaining at $40^{\circ} \mathrm{C} \pm 2^{\circ} \mathrm{C}$ and $75 \% \pm 5 \% \mathrm{RH}$. Samples were withdrawn at defined time intervals and investigated for changes in physical appearance, drug content, buoyancy and in vitro drug release as per ICH Q1A guidelines. ${ }^{22}$

\section{RESULTS}

\section{Compatibility studies by FTIR}

All the characteristic IR peaks related to pure drug dicloxacillin sodium also appeared in the FTIR spectra of mixtures of drug with polymers. The FTIR spectras were illustrated in Figures 1-3.

Analytical method development

The standard graph of dicloxacillin sodium was constructed using $0.1 \mathrm{~N}$ $\mathrm{HCl}$ in the range of $1-6 \mu \mathrm{g} / \mathrm{ml}$ and is shown in the Table 1 and Figure 4.

\section{Evaluation of precompression parameters}

\section{Angle of repose}

The angle of repose of all formulations was carried out and results reported in Table 3 , which ranges between $25.58^{\circ} \mathrm{C}-28.65^{\circ} \mathrm{C}$. The optimized formulation $\mathrm{F} 3$ showed the angle of repose $25.58^{\circ} \mathrm{C}$.

\section{Carr's index}

Carr's index of all the formulations was determined and the results were reported in Table 3, which ranges between $10.26 \%-14.64 \%$. The optimized formulation F3 showed carr's index of $12.11 \%$ 


\section{Hausner's ratio}

Hausner ratio for all the formulations was found to be in the range of 1.10-1.17. The optimized formulation F3 showed hausner's ratio of 1.12.

\section{Evaluation of post compression parameters}

\section{Thickness and Weight variation}

The thickness of all tested tablets was within the range of 4.48-4.81 mm. All the formulations passed weight variation test as the $\%$ weight variation was within the standard pharmacopeia limits of $\pm 5 \%$ of the weight.

\section{Drug content}

In order to estimate the amount of drug in each tablet for the therapeutic activity of Dicloxacillin sodium, the prepared tablets were evaluated for drug content and the drug content of all the fornulations were found to be in the range from $98.33 \%-100 \%$.

\section{Hardness and friability}

The hardness of tablets of each tested batch was in the range of 6.8-7.8 $\mathrm{kg} / \mathrm{cm}^{2}$. This ensures good handling characteristics for all formulations. The Percentage friability was less than $0.5 \%$ in all the formulations ensuring that all tablets were mechanically stable.

\section{Swelling studies}

The swelling index of all formulations was found to be in the range of $76.65 \%-92.65 \%$. The optimized formulation showed the swelling index of $92.65 \%$ at the end of $8 \mathrm{~h}$ and tabulated in Table 5 .

\section{In vitro buoyancy study}

The floating ability of prepared formulations was evaluated in $0.1 \mathrm{~N} \mathrm{HCl}$. The time took for formulations to emerge (Buoyancy lag time) and the time for which formulations floated continuously on the medium (duration of buoyancy) were evaluated. F1, F2, F3 formulations floated in $58,86,90$ secs and total floating time of $8,10,12 \mathrm{~h}$. F4, F5, F6 formulations floated in 65, 78, 80 secs and total floating time of 9, 11, 12. F7, F8, F9 formulations floated in $68,75,125$ secs and total floating time of 9, 10, 12 h. Respectively and tabulated in Table 4

\section{In vitro Dissolution Study}

In vitro drug release of formulations F1, F2, F3 were found to be $78.53 \%$ in $8 \mathrm{hr}, 92.36 \%$ in $10 \mathrm{hr}, 98.87 \%$ in $12 \mathrm{hrs}$. The drug release of F4, F5, F6 was found to be $98 \%$ in $9 \mathrm{hr}, 88.69 \%$ in $11 \mathrm{~h}, 93 \%$ in $12 \mathrm{hrs}$. In vitro drug release of F7, F8, F9 were found to be $94 \%$ in 9 hrs. $98.04 \%$ in $10 \mathrm{~h}$, 93.76\% in $12 \mathrm{hr}$ and the results were depicted in Figure 5

\section{Kinetic modeling of drug release}

Zero order, First order, Higuchi and Korsmeyer-peppas plots were plotted for the optimized formulation F3 and the results were shown in the Figures 6-9. Regression coefficients of these plots were shown in Table 6. $R^{2}$ values of Zero order of formulation F3 was found to be 0.993 .

\section{DISCUSSION}

The drug excipients interactions study was carried out using FTIR. The spectral data obtained showed that Dicloxacillin sodium was compatible with all the excipients used in the formulations. From FTIR studies, it was shown that there is no significant change in the nature and position of the characteristic band of drug and excipients used in the formulations, hence it can be concluded that there is no chemical interaction between drug and excipients as illustrated in Figure 1-3. The Standard graph of dicloxacillin sodium was plotted and it showed $R^{2}$ value of 0.9991 . The powder blend of drug and other excipients used for the formulation of Dicloxacillin floating tablets were evaluated for flow properties. The re- sults of optimized formulation F3 indicates that all the flow properties were good and in the acceptable range. Tablets prepared were round with creamy white color and smooth texture. The thickness of all tested tablets was within the range of $4.48-4.81 \mathrm{~mm}$. The hardness of tablets

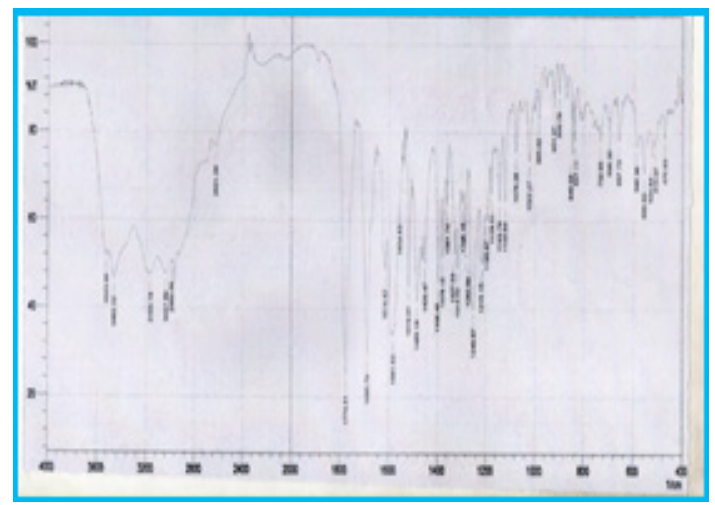

Figure 1: FTIR of Dicloxacillin sodium + HPMC K 100 M.

Table 1: Calibration Curve of Dicloxacillin sodium in $0.1 \mathrm{~N} \mathrm{HCl}$ at 263nm.

\begin{tabular}{ccc}
\hline S.NO & Concentration $(\mu \mathrm{g} / \mathrm{ml})$ & Absorbance \\
\hline 0 & 0 & 0 \\
1 & 1 & 0.134 \\
2 & 2 & 0.255 \\
3 & 3 & 0.372 \\
4 & 4 & 0.489 \\
5 & 5 & 0.611 \\
6 & 6 & 0.755 \\
\hline
\end{tabular}

Table 2: Formulation of floating tablets of Dicloxacillin sodium.

\begin{tabular}{|c|c|c|c|c|c|c|c|c|c|}
\hline $\begin{array}{l}\text { Ingredients } \\
\text { (mg) }\end{array}$ & F1 & F2 & F3 & F4 & F5 & F6 & F7 & F8 & F9 \\
\hline $\begin{array}{l}\text { Dicloxacillin } \\
\text { sodium }\end{array}$ & 270 & 270 & 270 & 270 & 270 & 270 & 270 & 270 & 270 \\
\hline HPMC K 100M & 220 & 240 & 260 & $\ldots$ & $\ldots$ & $\ldots$ & $\ldots$ & $\ldots$ & $\ldots$ \\
\hline Xanthan gum & $\ldots$ & $\ldots$ & $\ldots$ & 220 & 240 & 260 & $\ldots$ & $\ldots$ & $\ldots$ \\
\hline Guar gum & $\ldots$ & $\ldots$ & $\ldots$ & $\ldots$ & $\ldots$ & $\ldots$ & 220 & 240 & 260 \\
\hline $\begin{array}{l}\text { Microcrystalline } \\
\text { cellulose }\end{array}$ & 136 & 116 & 96 & 136 & 116 & 96 & 136 & 116 & 96 \\
\hline $\begin{array}{c}\text { Sodium } \\
\text { bicarbonate }\end{array}$ & 30 & 30 & 30 & 30 & 30 & 30 & 30 & 30 & 30 \\
\hline Citric acid & 20 & 20 & 20 & 20 & 20 & 20 & 20 & 20 & 20 \\
\hline Starch & 10 & 10 & 10 & 10 & 10 & 10 & 10 & 10 & 10 \\
\hline $\begin{array}{l}\text { Magnesium } \\
\text { Stearate }\end{array}$ & 7 & 7 & 7 & 7 & 7 & 7 & 7 & 7 & 7 \\
\hline Talc & 7 & 7 & 7 & 7 & 7 & 7 & 7 & 7 & 7 \\
\hline Total weight & 700 & 700 & 700 & 700 & 700 & 700 & 700 & 700 & 700 \\
\hline
\end{tabular}


Table 3: Precompression parameters for formulations F1-F9.

\begin{tabular}{|c|c|c|c|c|c|}
\hline $\begin{array}{l}\text { Formulation } \\
\text { code }\end{array}$ & $\begin{array}{c}\text { Angle of } \\
\operatorname{Repose}(\theta) \pm S D^{*}\end{array}$ & $\begin{array}{l}\text { Bulk Density } \\
(\mathrm{g} / \mathrm{ml}) \pm S D^{*}\end{array}$ & $\begin{array}{l}\text { Tapped Density } \\
(\mathrm{g} / \mathrm{ml}) \pm \mathrm{SD}^{*}\end{array}$ & $\begin{array}{l}\text { Carr's Index } \\
(\%) \pm S D^{*}\end{array}$ & $\begin{array}{c}\text { Hausner } \\
\text { Ratio } \pm \text { SD* }\end{array}$ \\
\hline $\mathrm{F} 1$ & $25.58 \pm 0.14$ & $0.49 \pm 0.12$ & $0.54 \pm 0.12$ & $10.26 \pm 0.12$ & $1.10 \pm 0.12$ \\
\hline F2 & $26.15 \pm 0.15$ & $0.51 \pm 0.15$ & $0.58 \pm 0.14$ & $12.05 \pm 0.15$ & $1.13 \pm 0.21$ \\
\hline F3 & $25.58 \pm 0.14$ & $0.47 \pm 0.16$ & $0.54 \pm 0.13$ & $12.11 \pm 0.16$ & $1.12 \pm 0.19$ \\
\hline $\mathrm{F} 4$ & $28.65 \pm 0.12$ & $0.50 \pm 0.17$ & $0.57 \pm 0.19$ & $12.05 \pm 0.17$ & $1.11 \pm 0.20$ \\
\hline F5 & $27.43 \pm 0.20$ & $0.45 \pm 0.12$ & $0.52 \pm 0.12$ & $14.64 \pm 0.12$ & $1.17 \pm 0.19$ \\
\hline F6 & $26.96 \pm 0.15$ & $0.51 \pm 0.14$ & $0.57 \pm 0.12$ & $10.53 \pm 0.14$ & $1.12 \pm 0.13$ \\
\hline F7 & $27.10 \pm 0.21$ & $0.48 \pm 0.15$ & $0.55 \pm 0.12$ & $13.78 \pm 0.14$ & $1.16 \pm 0.18$ \\
\hline F8 & $26.01 \pm 0.77$ & $0.56 \pm 0.12$ & $0.64 \pm 0.003$ & $12.98 \pm 0.19$ & $1.14 \pm 0.19$ \\
\hline F9 & $28.63 \pm 0.11$ & $0.53 \pm 0.12$ & $0.60 \pm 0.01$ & $10.26 \pm 0.99$ & $1.11 \pm 0.15$ \\
\hline
\end{tabular}

${ }^{*} n=3$ All values are expressed as mean \pm SD

Table 4: Evaluation of post compression parameters.

\begin{tabular}{|c|c|c|c|c|c|c|c|}
\hline Formulation code & $\begin{array}{c}\text { Average } \\
\text { Weight }(\mathrm{mg}) \pm S D^{*} \\
(n=20)\end{array}$ & $\begin{array}{l}\text { Thickness } \\
(\mathrm{mm}) \pm S D^{*} \\
(n=3)\end{array}$ & $\begin{array}{l}\text { Friability } \\
\quad(w / w) \\
\pm S D^{*}(n=3)\end{array}$ & $\begin{array}{l}\text { Content Uniformity } \\
(\%) \pm S D^{*}(n=10)\end{array}$ & $\begin{array}{l}\text { Hardness }(\mathrm{kg} / \\
\mathrm{cm} 2) \pm \mathrm{SD}^{*}(n=6)\end{array}$ & $\begin{array}{l}\text { Floating Lag } \\
\text { time } S D^{*}(\mathrm{sec}) \\
(n=3)\end{array}$ & $\begin{array}{c}\text { Total floating } \\
\text { Time SD* (h) } \\
(n=3)\end{array}$ \\
\hline F1 & $700.2 \pm 0.15$ & $4.52 \pm 0.13$ & $0.45 \pm 0.13$ & $98.33 \pm 0.18$ & $7.8 \pm 0.21$ & $58 \pm 0.21$ & $8 \pm 0.12$ \\
\hline $\mathrm{F} 2$ & $699.2 \pm 0.14$ & $4.61 \pm 0.14$ & $0.28 \pm 0.13$ & $99 \pm 0.18$ & $7.4 \pm 0.14$ & $86 \pm 0.12$ & $10 \pm 0.15$ \\
\hline F3 & $700.3 \pm 0.13$ & $4.68 \pm 0.12$ & $0.41 \pm 0.15$ & $99.67 \pm 0.15$ & $7.2 \pm 0.15$ & $90 \pm 0.14$ & $12 \pm 0.12$ \\
\hline F4 & $699 \pm 0.17$ & $4.81 \pm 0.13$ & $0.38 \pm 0.12$ & $100 \pm 0.13$ & $7.4 \pm 0.14$ & $65 \pm 0.16$ & $9 \pm 0.12$ \\
\hline F5 & $699.9 \pm 0.18$ & $4.72 \pm 0.12$ & $0.36 \pm 0.17$ & $99.33 \pm 0.19$ & $7.1 \pm 0.13$ & $78 \pm 0.12$ & $11 \pm 0.15$ \\
\hline F6 & $699 \pm 0.21$ & $4.69 \pm 0.12$ & $0.48 \pm 0.19$ & $99.33 \pm 0.18$ & $6.8 \pm 0.21$ & $80 \pm 0.17$ & $12 \pm 0.14$ \\
\hline F7 & $699.8 \pm 0.15$ & $4.48 \pm 0.15$ & $0.46 \pm 0.12$ & $99.67 \pm 0.21$ & $7.4 \pm 0.16$ & $68 \pm 0.12$ & $9 \pm 0.12$ \\
\hline F8 & $700.7 \pm 0.19$ & $4.52 \pm 0.15$ & $0.38 \pm 0.14$ & $99 \pm 0.19$ & $7.8 \pm 0.18$ & $75 \pm 0.13$ & $10 \pm 0.14$ \\
\hline F9 & $699.7 \pm 0.20$ & $4.51 \pm 0.20$ & $0.36 \pm 0.13$ & $98.33 \pm 0.15$ & $7.5 \pm 0.19$ & $125 \pm 0.19$ & $12 \pm 0.14$ \\
\hline
\end{tabular}

Table 5: Swelling Index (\%) of formulations F1- F9.

\begin{tabular}{ccccccccccc}
\hline \multirow{2}{*}{$\begin{array}{c}\text { TIME } \\
\text { (hr) }\end{array}$} & \multicolumn{7}{c}{ Swelling index (\%) \pm SD* } \\
\cline { 2 - 9 } & F1 & F2 & F3 & F4 & F5 & F6 & F7 & F8 \\
\hline 1 & $10.31 \pm 0.12$ & $12.89 \pm 0.14$ & $13.05 \pm 0.15$ & $11.24 \pm 0.20$ & $13.24 \pm 0.14$ & $14.54 \pm 0.18$ & $10.58 \pm 0.15$ & $13.78 \pm 0.17$ & $14.99 \pm 0.14$ \\
2 & $21.42 \pm 0.15$ & $23.5 \pm 0.12$ & $35.7 \pm 0.16$ & $25.89 \pm 0.15$ & $28.10 \pm 0.16$ & $30.35 \pm 0.15$ & $22.78 \pm 0.18$ & $27.45 \pm 0.19$ & $29.6 \pm 0.16$ \\
3 & $28.15 \pm 0.14$ & $32.15 \pm 0.15$ & $48.23 \pm 0.15$ & $34.15 \pm 0.12$ & $38.45 \pm 0.17$ & $43.46 \pm 0.14$ & $33.0 \pm 0.17$ & $43.46 \pm 0.15$ & $47.25 \pm 0.13$ \\
4 & $39.63 \pm 0.13$ & $45.25 \pm 0.14$ & $56.13 \pm 0.12$ & $49.3 \pm 0.15$ & $52.74 \pm 0.19$ & $56.4 \pm 0.17$ & $43.86 \pm 0.14$ & $52.5 \pm 0.19$ & $56.35 \pm 0.15$ \\
5 & $48.05 \pm 0.20$ & $59.5 \pm 0.18$ & $75.7 \pm 0.14$ & $56.23 \pm 0.14$ & $61.3 \pm 0.21$ & $69.45 \pm 0.19$ & $54.0 \pm 0.16$ & $63.45 \pm 0.20$ & $66.5 \pm 0.16$ \\
6 & $57.63 \pm 0.16$ & $68.47 \pm 0.19$ & $83.74 \pm 0.17$ & $61.32 \pm 0.17$ & $70.51 \pm 0.19$ & $77.36 \pm 0.21$ & $67.85 \pm 0.16$ & $71.36 \pm 0.14$ & $79.47 \pm 0.17$ \\
7 & $69.67 \pm 0.19$ & $77.6 \pm 0.20$ & $89.5 \pm 0.18$ & $70.8 \pm 0.21$ & $78.1 \pm 0.14$ & $84.85 \pm 0.18$ & $74.45 \pm 0.18$ & $80.75 \pm 0.17$ & $85.6 \pm 0.16$ \\
8 & $76.65 \pm 0.18$ & $83.6 \pm 0.19$ & $92.65 \pm 0.19$ & $75.1 .8 \pm 0.17$ & $80.33 \pm 0.19$ & $89.06 \pm 0.19$ & $79.45 \pm 0.19$ & $86.75 \pm 0.19$ & $90.45 \pm 0.18$ \\
\hline
\end{tabular}


Table 6: Release Kinetics Studies for all formulations.

\begin{tabular}{|c|c|c|c|c|c|}
\hline \multicolumn{6}{|c|}{$R^{2}$} \\
\hline Formulation & Zero & First & Higuchi & Peppa's & Peppa's \\
\hline Code & Order & order & & & $n$-values \\
\hline $\mathrm{F} 1$ & 0.982 & 0.936 & 0.662 & 0.982 & 0.746 \\
\hline $\mathrm{F} 2$ & 0.984 & 0.875 & 0.774 & 0.989 & 0.812 \\
\hline F3 & 0.993 & 0.813 & 0.662 & 0.992 & 0.862 \\
\hline $\mathrm{F} 4$ & 0.981 & 0.792 & 0.755 & 0.981 & 0.781 \\
\hline F5 & 0.983 & 0.971 & 0.736 & 0.975 & 0.832 \\
\hline F6 & 0.974 & 0.890 & 0.732 & 0.989 & 0.846 \\
\hline F7 & 0.975 & 0.898 & 0.646 & 0.974 & 0.536 \\
\hline F8 & 0.984 & 0.741 & 0.834 & 0.992 & 0.739 \\
\hline F9 & 0.988 & 0.890 & 0.701 & 0.988 & 0.836 \\
\hline
\end{tabular}

Table 7: Accelerated stability studies for F3 formulation.

\begin{tabular}{|c|c|c|c|c|c|}
\hline S.NO & Test & Initial & After 1 month & After 2 months & After 3 months \\
\hline \multirow[t]{2}{*}{1} & Description & Creamy white & Creamy white & Creamy white & Creamy white \\
\hline & & colour & colour & colour & colour \\
\hline 2 & Floating lag time (Sec) & $90 \pm 0.14$ & $90 \pm 0.07$ & $90 \pm 0.010$ & $90 \pm 0.12$ \\
\hline 3 & Total floating time (hr) & $12 \pm 0.12$ & $12 \pm 0.09$ & $12 \pm 0.11$ & $12 \pm 0.12$ \\
\hline 4 & $\%$ Drug release & $98.87 \%$ & $98.85 \%$ & $98.82 \%$ & $98.81 \%$ \\
\hline 5 & Drug content (\%) & $99.67 \%$ & $99.67 \%$ & $99.65 \%$ & $99.65 \%$ \\
\hline
\end{tabular}

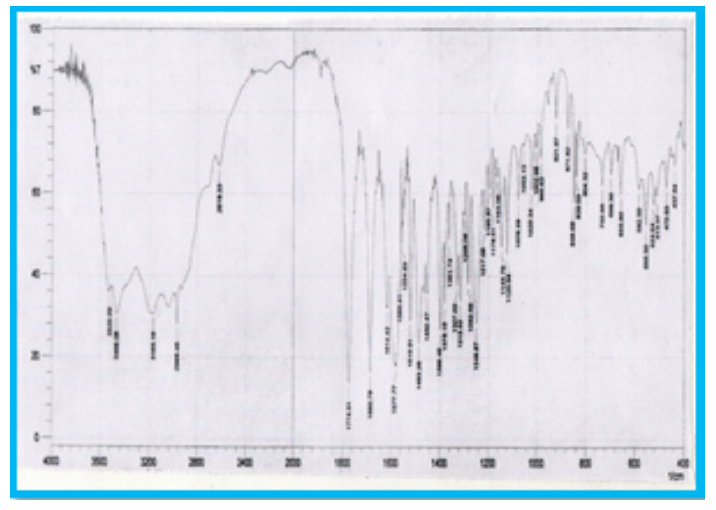

Figure 2: FTIR of Dicloxacillin sodium + Xanthan gum.

of each tested batch ranged between $6.8-7.8 \mathrm{~kg} / \mathrm{cm}^{2}$ and values were tabulated in Table 4 . This ensures good handling characteristics for all formulations. The Percentage friability was less than $0.5 \%$ in all the formulations ensuring that all tablets were mechanically stable. The weights of all the tablets were found to be uniform. Floating lag time and total floating time was evaluated for all the formulations. The floating ability of prepared formulations was evaluated in $0.1 \mathrm{~N} \mathrm{HCl}$. Formulations F1, F4, F7 shown less floating lag time and the total floating time was less than $10 \mathrm{~h}$. An increase in the polymer ratio in the formulations F2, F5, F8 and F3, F6, F9 increased the floating lag time and the total floating time. F3, F6 and F9 formulations floated within 90, 80 and 125secs and have good buoyancy for 12, 12, 12 respectively. Thus, from the results it was observed that an increase in the concentration of polymers increased the total floating time of the tablets. ${ }^{23}$ The swelling index was performed for

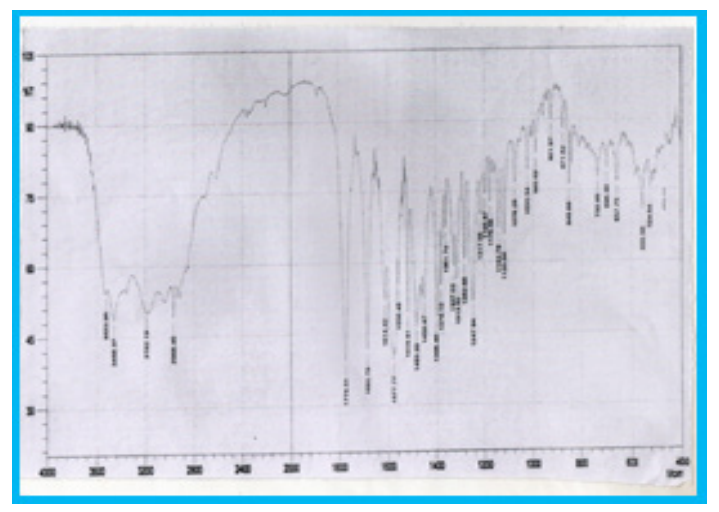

Figure 3: FTIR of Dicloxacillin sodium + Guar gum.

all the formulations. The swelling index was increased with an increase in the polymer concentration. The F3 formulation containing HPMC K100 M shown the maximum swelling index of $92.65 \%$, this could be due to the hydrophilic nature of the polymer. ${ }^{24}$ In vitro drug release studies were conducted in the dissolution medium of $0.1 \mathrm{~N} \mathrm{HCl}$. Formulations F1, F4, F7 containing different polymers having drug: polymer ratio of 1:0.81 could not able to release the drug for $12 \mathrm{~h}$ and shown the drug release of $78.53 \%, 98 \%, 94.09 \%$ in 8, 9, $9 \mathrm{hr}$ respectively. An increase in the polymer concentration in the formulations F2, F5, F8 able to release the drug for a period of $10-11 \mathrm{hr}$ and shown the drug release of $92.36 \%$, $88.69 \%, 98.04 \%$ respectively. Formulations F3, F6, F9 can able to release the drug upto $12 \mathrm{hr}$. When compared with the formulations F6 and F9 containing Xanthan gum and guar gum, formulation F3 containing HPMC K 100 M of drug :Polymer ratio of 1:0.96 shown the drug release 


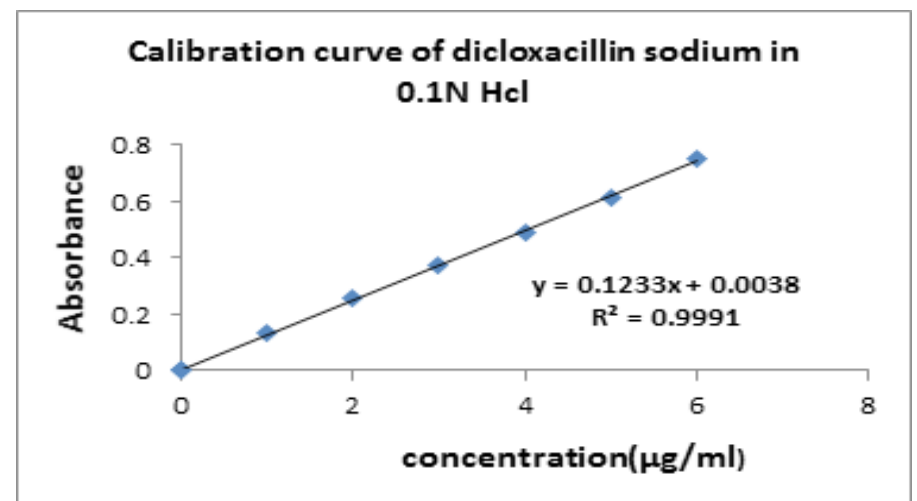

Figure 4: Calibration curve of dicloxacillin sodium in $0.1 \mathrm{~N} \mathrm{HCl}$.

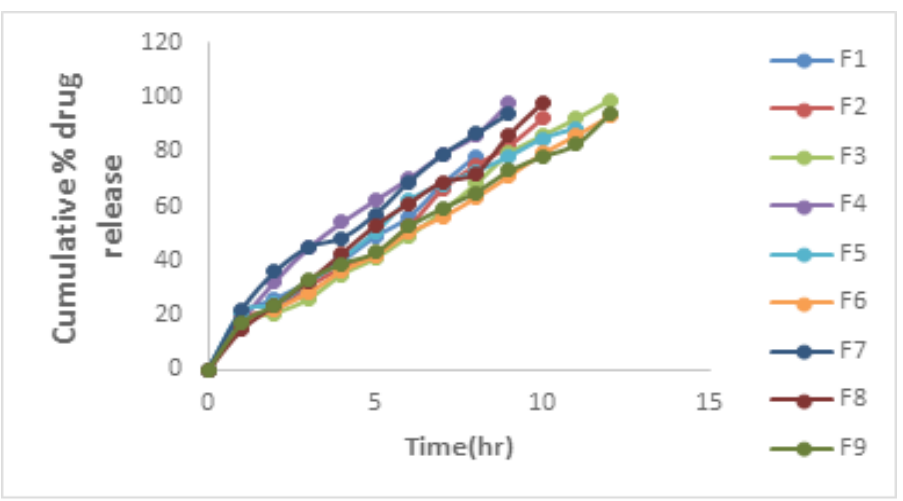

Figure 5: Drug release profile of the Dicloxacillin sodium floating tablets.

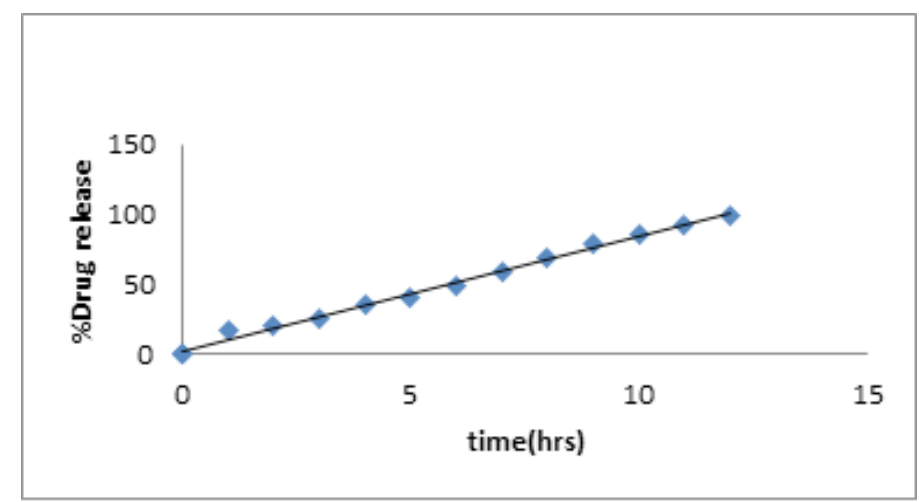

Figure 6: Zero order kinetics of the optimized formulation F3.

of $98.87 \%$ at the end of $12 \mathrm{hr}$. This clearly suggests that an increase in the concentration of the polymer retarded the drug release up to $12 \mathrm{hr}^{25}$ Zero order, First order, Higuchi and Korsmeyer-peppas plots were plotted for the optimized formulation F3 and were shown in the Figures 6-9. Regression coefficients of these plots were shown in Table 6. $R^{2}$ values of Zero order (0.993) for optimized formulation (F3) were greater than $R^{2}$ values of First order (0.813). Hence the drug release follows Zero order kinetics. The $\mathrm{n}$ value of koresmeyer peppas plot for $\mathrm{F} 3$ formulation was found to be 0.862 . This suggests that it follows non fickian mechanism. The 3 months accelerated stability data indicates that the formulation F3 is stable interms of physical appearance, drug content, dissolution and buoyancy as represented in Table 7 .

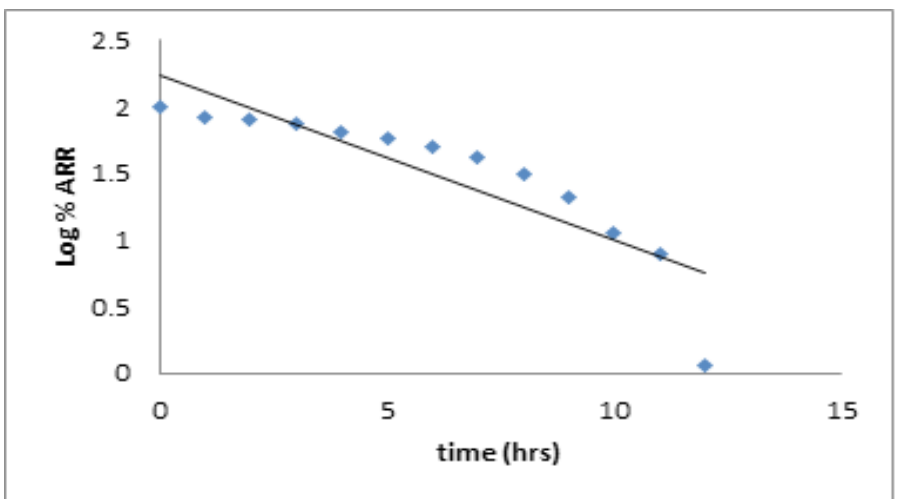

Figure 7: First order kinetics of the optimized formulation F3.

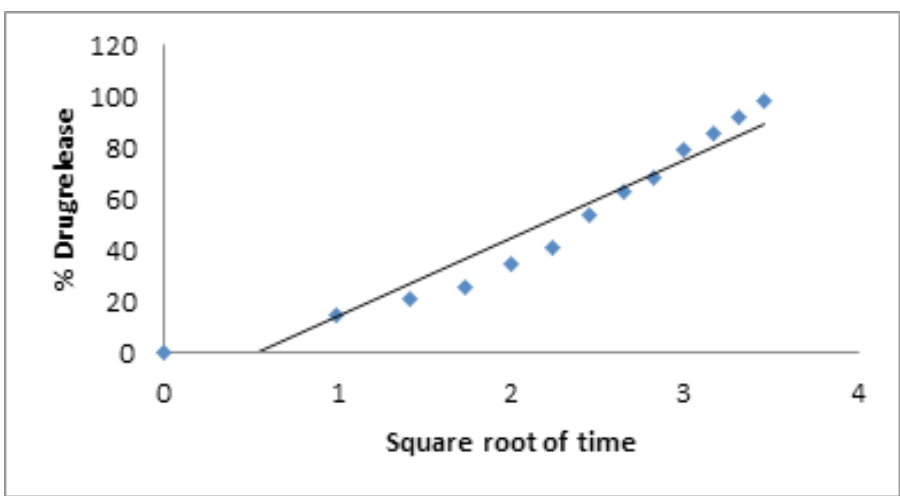

Figure 8: Higuchi model for the optimized formulation F3.

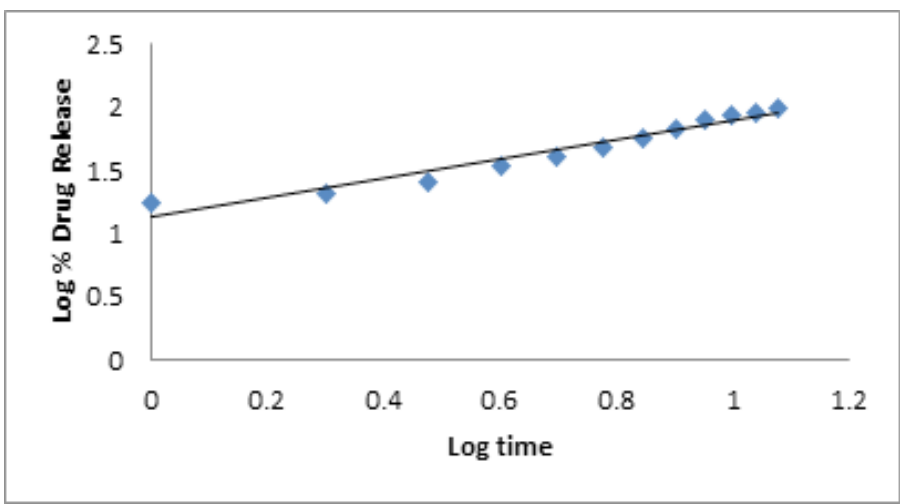

Figure 7: Korsmeyer-peppas model for the optimized formulation F3.

\section{CONCLUSION}

Gastroretentive floating tablets of Dicloxacillin sodium were successfully prepared by using wet granulation method employing HPMC K 100 M, xanthan gum, guar gum in different ratios. Among all the formulations, F3 has shown $98.87 \%$ controlled drug release at the end of $12 \mathrm{hr}$. The floating lag time of optimized formulation F3 was $90 \pm 0.15 \mathrm{sec}$. Stability studies of the F3 formulation was performed according to ICH guidelines for 3 months and no major changes were observed indicated that the F3 formulation was stable and can be considered as the promising formulation. 


\section{ACKNOWLEDGEMENT}

The authors are thankful to the management of Raghavendra Institute of Pharmaceutical Education \& Research for providing facilities to carry out the work.

\section{CONFLICT OF INTEREST}

The authors declare no conflict of interest.

\section{ABBREVIATIONS}

HPMC: Hydroxyproypl methylcellulose; GRT: Gastric residence time; MCC: Microcrystalline cellulose; FTIR: Fourier-transform infrared spectroscopy; USP:United states of pharmacopoeia.

\section{REFERENCES}

1. Saritha D, Sathish D, Rao YM. Formulation and evaluation of gastroretentive floating tablets of domperidone maleate. J App Pharma Sci. 2012;2(3):68-73.

2. Jagdale SC, Agavekar AJ, Pandya SV, Kuchekar BS, Chabukswar AR. Formulation and evaluation of gastroretentive drug delivery system of propranolo hydrochloride. AAPS Pharm Sci Tech. 2009;10(3):1071-6.

3. Prakash U, Singh L, Sharma V. Role of xanthan gum (xanthomonas compestris) in gastroretentive drug delivery system: An overview. Int Res J Pharm. 2016;4(4):35-8.

4. Singh PK. Bilayer and Floating-Bioadhesive Tablets: Innovative approach to gastroretension. Journal of Drug Delivery and Therapeutics. 2011;1(1):32-5

5. Sathiyaraj S, Devi RD, Hari VB. Lornoxicam gastro-retentive floating matrix tablets: Design and in vitro evaluation. J Adv Pharm Technol Res. 2011;2(3):156-62.

6. Arora S, Ali J, Ahuja A, Khar RK, Baboota S. Floating drug delivery systems: A review. AAPS Pharm Sci Tech. 2005;6(3):372-90.

7. Wu G, Zheng Y, Zhou H, Hu X, Liu J, Zhai Y, et al. Safety and pharmacokinetics of dicloxacillin in healthy Chinese volunteers following single and multiple oral doses. Drug Des Devel Ther. 2015;9(1):5687-95.

8. Pavan M, Prasanth K, Abhishek S, Ajay C, Rinku M, Sam T. Formulation and evaluation of dicloxacillin sodium floating tablets. Res Rev J Pharm Pharma Sci. 2014;3(2):7-15.

9. Shukr M, Reheem AA. Development and evaluation of ketorolac tromethamine mucoadhesive buccal tablets. Int J Pharm Pharma Sci. 2014;6(8):294-8.

10. Tiwari AK, Rabadia N. Formulation and optimization of effervescent floating tablet of diltiazem hydrochloride using response surface methodolgy. J Pharm
Res. 2012:5(7):3506-14

11. Supriya $S$, Nilima T, Sagar A. Effect of hydrophilic polymer on buoyancy of floating tablets prepared by wet granulation technique using Musa paradisiaca starch. Int J Pharma Sci Res. 2017;8(10):195-201.

12. Meka VS, Dharmanlingam SR, Kolapalli VR. Formulation of gastroretentive floating drug delivery system using hydrophilic polymers and its in vitro characterization. Braz J Pharma Sci. 2014;50(2):431-9.

13. Malisetty SC, Allena RT, Sandina S, Gangadharappa HV. Formulation and evaluation of modified-release effervescent floating tablets of ofloxacin. Int J Health Allied Sci. 2013;2(2):99-107.

14. Shah RB, Tawakkul MA, Khan MA. Comparative evaluation of flow for pharmaceutical powders and granules. AAPS Pharmscitech. 2008;9(1):250-8.

15. Chowdhary R, Pai RS, Singh G. Development and evaluation of 6-mercaptopurine and metoclopramide polypill formulation for oral administration: in-vitro and ex vivo studies. Int J Pharma Investig. 2013;3(4):217-24.

16. Patel A, Dodiya H, Shelate P, Shastri D, Dave D. Design, characterization and optimization of controlled drug delivery system containing antibiotic drugs. Drug Deliv. 2016;1(1):1-15.

17. Pawar HA, Dhavale R. Development and evaluation of gastroretentive floating tablets of an antidepressant drug by thermoplastic granulation technique. BeniSuef University: Int J Basic Api Sci. 2014;3(2):122-32.

18. Jagdale SC, Patil S, Kuchekar BS. Application of design of experiment for floating drug delivery of tapentadol hydrochloride. Comput Math Methods Med. 2013;1(3):1-7.

19. Haranath C, Raveendra RJ Devanna N Preparation and in vitro evaluation of floating tablets using biodegradable polymers. Int J Pharm Bio Sci. 2017;8(2):248-57.

20. Mughal MA, lqbal Z, Neau SH. Guar gum, xanthan gum and HPMC can define release mechanisms and sustain release of propranolol hydrochloride. AAPS Pharmscitech. 2011;12(1):77-87.

21. Costa P, Lobo JM. Modeling and comparison of dissolution profiles. Eur J Pharma Sci. 2001;13(2):123-33.

22. Chakraborty TN, Saini VR. Formulation and evaluation of controlled release floating tablets of cefixime using hydrophilic polymers. Int Res J Pharm. 2019;10(1):171-5.

23. Chavanpatil MD, Jain P, Chaudhari S, Shear R, Vavia PR. Novel sustained re lease, swellable and bioadhesive gastroretentive drug delivery system for ofloxacin. Int J Pharma. 2006:1(2):86-92.

24. Pawar HA, Gharat PR, Dhavale RV, Joshi PR, Rakshit PP. Development and evaluation of gastroretentive floating tablets of an antihypertensive drug using hydrogenated cottonseed oil. ISRN Pharmaceutics. 2013;1(1):1-9.

25. Arza RA, Gonugunta CS, Veerareddy PR. Formulation and evaluation of swellable and floating gastroretentive ciprofloxacin hydrochloride tablets. AAPS Pharm Sci Tech. 2009;10(1):220-6.

Article History: Submission Date : 06-05-2019; Revised Date : 23-06-2019; Acceptance Date : 26-06-2019.

Cite this article: Haranath C, Barghav GC, Reddy CM, Pradeepkumar B, Ahad HA. Formulation and in vitro Evaluation of Floating Tablets of Dicloxacillin Sodium Using Different Polymers. J Young Pharm. 2019;11(3):248-53. 